\title{
Current Concepts in Bone Graft Substitutes
}

\author{
Marie Leteve, Norbert Passuti \\ Orthopaedic Department of Nantes, University Hospital Hotel Dieu, Nantes, France \\ Email: lemauffmarie@gmail.com, norbert.passuti@chu-nantes.fr
}

How to cite this paper: Leteve, M. and Passuti, N. (2018) Current Concepts in Bone Graft Substitutes. New Journal of Glass and Ceramics, 8, 39-54.

https://doi.org/10.4236/njgc.2018.83004

Received: July 9, 2018

Accepted: July 27, 2018

Published: July 30, 2018

Copyright $(9) 2018$ by authors and Scientific Research Publishing Inc. This work is licensed under the Creative Commons Attribution International License (CC BY 4.0).

http://creativecommons.org/licenses/by/4.0/

\begin{abstract}
Purpose: Bone grafting is still requested to fill bone defects in traumatology, or after tumor removal, but also in orthopedic surgery for spine, arthroplasty revisions, and osteotomies. Due to the limitations of autografts and allografts, and the progress of biomaterial research, a large number of nonhuman bony scaffolds have been developed including synthetic calcium phosphates and highly processed xenografts. The most important parameters for bone ingrowth are the macroporosity of the scaffold with the suitable biological autologous cells and factors, optimal osteoinductive, osteointegrative and osteoconductive properties can be achieved. Methods and Results: The important factors regulating these properties are discussed in this paper, which also reports preclinical and clinical results obtained with such bone graft substitutes. Conclusions: Among different bone graft substitutes available, the porosity, the accessibility of pores, the internal surface exposed to the biological components of bone repair, are present in highly processed bovine hydroxyapatites. Compared to autografts, allografts and synthetic substitutes, they associate an initial conductivity, and a long term stability suitable for some orthopedic indications.
\end{abstract}

\section{Keywords}

Bone Graft Substitutes, Xenograft, Hydroxyapatite, Spine, Review

\section{Introduction}

Today, the treatment of large bone defects frequently employs the use cortical and cancellous bone graft. For this, orthopedic surgeons often use either allografts or autografts [1] [2]. The advantages of allografts come not without risk of complications, particularly contaminations that may result in hepatitis or acquired immunological deficiency syndrome (AIDS). While an autograft procedure eliminates the risk of such contamination, significant morbidity at the donor site is not uncommon, including hematoma, septic complications and po- 
tentially long-term pain [3].

Besides patient related drawbacks associated with an autograft, bone harvest increases surgery time and available autologous bone quantity is frequently not sufficient to fill the defect. For these reasons, alternative, non-autologous bone graft substitutes have more recently been the graft material of choice to fill large bone defects in orthopedic surgery.

Indeed, bone substitute materials are currently available for a variety of indications in orthopedic surgery. The number of products and the amount of published information about them can present a challenge when selecting a bone graft substitute. Thus, this review focuses on specific parameters that are prone to influence biological interaction and graft performance to aid the decision making process.

Graft substitutes may be grouped as synthetic (predominantly osteoconductive) or biologic (predominantly osteoinductive) and important parameters for assessing how a bone substitute may perform in vivo are: biocompatibility, osteoconductivity, osseointegration, kinetic of resorption and osteoinductivity [4].

In general, when a material is considered to be biocompatible, this implies that it harmonizes with the environment in situ, is not perceived as a foreign body, and thus does not produce adverse events. The bioactivity is described as the occurrence of an interaction between a biomaterial and the living tissue. Bioactivity is measured by the attachment and differentiation of osteogenic cells on material surfaces. Thus, osteogenic materials have the intrinsic capacity to stimulate bone healing [5].

Osteoconductivity refers to a property of the material describing how well it promotes bone tissue ingrowth. Here, macroporosity is a major factor that influences bone formation and differentiation, ultimately leading to osseointegration of the material. Osteoconduction is the ability of a material to provide a scaffold for bone formation, the surface of the substitute provides conditions for cells to proliferate and deposit bone matrix, mostly collagen type I, the porosity of the biomaterial should be favorable to the microvascularization (pores more than 100 microns) and the survival of these cells.

Another important feature of a bone substitute material is it resorption kinetics. Rapid resorption will leave the defect without proper osteoconductive active material and thus impair bone formation. In some conditions, bone tissue differentiation is observed combined with formation of a new mineral phase linked to the bioactivity of the respective bone substitute material used (microporosity and ions release). Finally, osteoinduction refers to materials that triggers formation of new osteoblasts and are able to induce bone tissue formation in non-osseous sites, such as intra-muscular or subcutaneous [4]. Osteinduction implies a mechanism by which mesenchymal tissue is induced to change its cellular structure to become osteogenic and to develop bone [5].

This review is dedicated to the assessment of bone substitutes commonly used in orthopedic surgery. Specifically, we address the grafts themselves as well as 
the properties governing their performance.

\section{Critical Analysis of Different Bone Substitutes}

\subsection{Allogenic Bone Grafts}

Human allograft bone contains some inductive bone morphogenic proteins which could activate bone cells and also conductive properties but not real inductive properties due to absence of cells [6].

Main advantages of harvested allograft are the availability considering different volumes and shape and avoidance the donor-site morbidity of autologous graft. But there is some debate due to the possible transmission of infectious agents which could be eliminated by sterilization. Conservation and storage are others limiting factors [7]. Frozen grafts can be selected from different bone banks and contains different growth factors. The bone marrow is defatted and allows to maintain mechanical properties, in contrary freeze-dried bone is less resistant but can be stored at room temperature. We should keep in mind that some known cases of HIV, hepatitis $\mathrm{C}$ and unknown viral diseases have been reported [8].

\subsection{Autologous Bone Grafts}

The principal advantage of autologous cancellous grafts is that potential osteoprogenitor cells are transferred to the recipient site. The theoretical advantage of osteogenic, osteoconductive and osteoinductive properties is diminished through the fact that the respective cells inside the autograft will not survive longer than $2 \mathrm{~h}$ [9]. Thus, the time interval between harvesting and transplantation of the graft is an important factor [10]. Autogenous bone grafts retain their viability for $2 \mathrm{~h}$ when kept in normal saline [11]. The graft remains unchanged in shape and acts as a passive scaffold for new bone growth to fill the defect even after autoclaving, but freeze-drying of autogenous bone did not alter the normal repair process associated with fresh autografts [12].

The transplantation process affects not only viability of the cells but also destroys the structure of the graft, which in its natural organization would have effectively supported the ingrowth of blood vessels as well as infiltration of osteoblasts and their precursors [13]. The cancellous graft does not provide immediate structural support. It integrates quickly, and ultimately achieves strength equivalent to a cortical graft within 6 - 12 months [14].

\subsection{Demineralized Bone Matrix (DBM)}

DBM, also called human demineralized freeze-dried bone allograft, has osteoconductive and osteoinductive potential. Demineralization of bone is an achieved by acid extraction of allograft material, leading to the loss of the allograft's inherent antigenicity whilst retaining collagen and various proteins. The bioactivity of DBM is linked to these proteins comprising growth factors such as bone morphogenetic proteins (BMPs). The osteoinductive properties of DBM 
are affected by storage, processing and sterilization techniques and may vary from donor to donor. Recent publications confirm the high variations of results with DBMs [15] [16]. Further, a review article accurately demonstrated that significant variations in the residual concentrations of BMPs exist when comparing preparations to each other and within various lots of the same preparation [17].

Because DBM is derived from human tissue, it disease transmission rates are probably similar to fresh allografts [17]. However, it has to be stated that transmission of diseases has not yet been reported.

Concerning the demineralization process, the techniques used are not published and the processes are not regulated. No efficacy testing is required from the FDA as it is neither a drug, nor a medical device, but rather a transformed human tissue [16].

\subsection{Non-Human Bone Graft Substitutes}

\subsubsection{Ceramic Based Bone Graft Substitutes}

Synthetic ceramics are prepared using classical ceramic techniques [18] [19]. The basic constituents are prepared by chemical synthesis and presented as a powder. Forming for clinical utilization is achieved through a variety of procedures. After calcination (heating to approximately $900^{\circ} \mathrm{C}$ ) the powder is compacted and then heated to between $1100^{\circ} \mathrm{C}$ and $1300^{\circ} \mathrm{C}$. This last thermal treatment, called sintering, has the double aim of consolidating and increasing the density of the piece being compacted. In the case of the calcium phosphate ceramics, maintenance of some porosity is necessary to conserve the properties of bioactivity and osteoconduction of the implant. Non sintered calcium phosphate substitutes are used only for their surface bioactive properties or for filling defects but not as porous materials.

There are two types of porosity that may result from the processing of synthetic ceramics. Microporosity with pore diameter less than 10 microns, results usually from spaces persisting between crystals of the biomaterial after sintering. Macroporosity with pore diameter greater than 100 microns is created deliberately in order to encourage penetration of cells and living tissue. It is obtained by adding hydrogen peroxide, naphthalene microspheres or a wax skeleton, which disappears during calcination, leaving pores of the desired volume in the material. It is also possible to obtain a porous calcium phosphate ceramic by changing other manufacturing parameters [18].

\subsubsection{Purified Xenograft Based Bone Graft Substitute}

Processed xenografts have been developed to provide a structural scaffold very similar to the natural bone, under the conditions of safety related to the xenogenic origin, biocompatibility depending of the removal of non-mineral components of the bone tissue (proteins, lipids, cells and residues of processing) [20].

Among them, the xenograft Orthoss ${ }^{\circledR}$ (Geistlich Pharma AG) is a bio-derived bone substitute made from highly purified bovine bone mineral. It is an inor- 
ganic bone matrix comprised of natural nanocrystalline carbonated hydroxyapatite: $\mathrm{Ca}_{10}\left(\mathrm{PO}_{4}\right)_{6}(\mathrm{OH})_{2}$. An important feature is the topography of this substitute which is similar to human bone with a high pore connectivity. Macroporosity of the xenograft is strictly similar to cancellous bone. Due to specially designed stepwise low heat and a chemical treatment, Orthoss ${ }^{\circledR}$ does not contain any organic component and its unique micro- and macroporous structure is not compromised (Figure 1, Figure 2). In addition, of the large interconnecting pores, very small pores $<1 \mu \mathrm{m}$ are largely observed on the surface of the granules (Figure 3).

\subsubsection{Chemical Properties}

The calcium phosphate ceramics are part of a large class of apatite characterized by the formula $\mathrm{M}_{10}\left(\mathrm{XO}_{4}\right) 6 \mathrm{Z}_{2}$. Apatite forms a large range of compounds. $\mathrm{Nu}$ merous substitutions of the calcium, phosphate or hydroxyl group are possible. These different substitutions modify the properties of the calcium phosphates, in particular their solubility [18] [19] [21]. Fluorapatite, obtained by substituting the $\mathrm{HO}^{-}$ion by the $\mathrm{F}^{-}$, has much less solubility than hydroxyapatite, while the presence of $\mathrm{CO}_{3}^{2-}$ and $\mathrm{Mg}^{2+}$ increases the solubility of hydroxyapatite. In tricalcium phosphates, substituting the $\mathrm{Ca}^{2+}$ by $\mathrm{Mg}^{2+}$ diminishes the solubility.

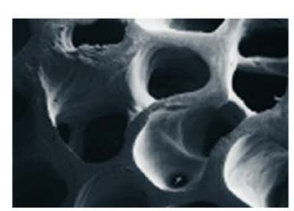

Human Bone

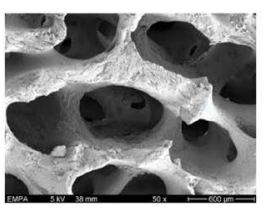

Orthoss $^{\circledR}$

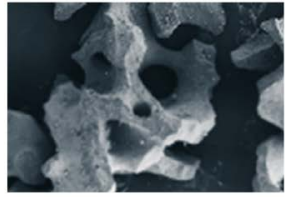

Sintered Bovine Bone

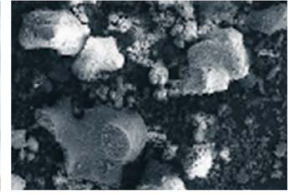

Synthetic Hydroxyapatite $\beta-T C P(S E M ~ 25 x)$

Figure 1. Micrographs of various bone graft substitutes showing microstructure (SEM $50 \mathrm{x})$. For sample preparation granules or sections of BGSs were placed on an aluminum sample holder and fixed with a conductive foil. Afterwards, the sample was sputtered with gold/palladium. Analysis of sputtered samples were done with a Phenom Pro X Desktop SEM (Thermo Scientific).

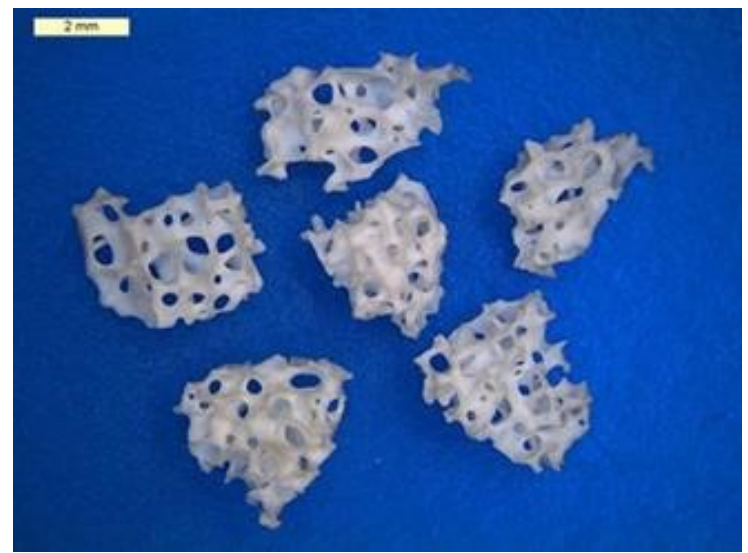

Figure 2. Macroscopic image of a bovine xenogeneic bone granules taken with a Leica MZ 6 stereomicroscope equipped with a Leica DFC295 digital camera and a Leica LED 1000 light source. 

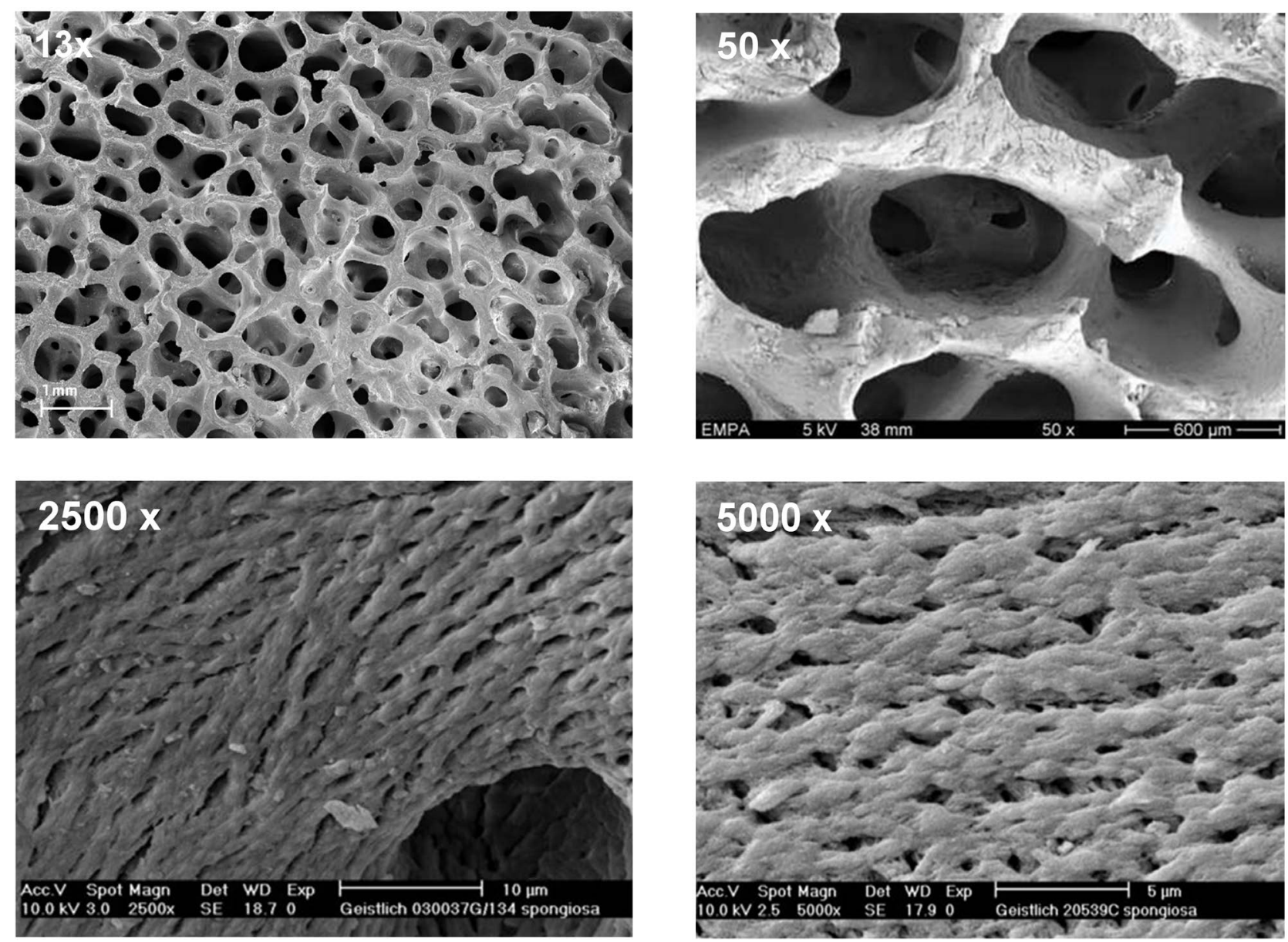

Figure 3. Scanning electron micrographs of deproteinized, porous xenograft at various magnifications showing interconnected macro-microporous structure of the graft. For sample preparation granules of BGS were placed on an aluminum sample holder and fixed with a conductive foil. Afterwards, the sample was sputtered with gold/palladium. Analysis of sputtered samples were done with a Phenom Pro X Desktop SEM (Thermo Scientific).

1) Hydroxyapatite (HA): $\mathrm{Ca}_{10}\left(\mathrm{PO}_{4}\right)_{6}(\mathrm{OH})_{2}$

This phosphate of calcium is the most similar to the biological apatite crystals. However, the $\mathrm{Ca} / \mathrm{P}$ atomic ration (1.67) is higher than that in powdered bone, dentine or dental enamel. Among all the calcium phosphate biomaterials, pure hydroxyapatite is the least soluble.

2) Beta tri-calcium phosphate ( $\beta$-TCP): $\mathrm{Ca}_{3}\left(\mathrm{PO}_{4}\right)_{2}$

This is characterized by a calcium phosphate atomic ratio of 1.5. $\beta \mathrm{TCP}$ is more soluble than pure HA.

3) The biphasic calcium phosphate (BCP)

Biphasic products are mixtures of HA and TCP. Their chemical properties depend on the proportions of these two constituents in the mixture. This determines the speed of resorption and bone substitutions of the ceramic. The higher the HA/TCP ratio, the less the solubility of the biphasic ceramic.

4) Bioactive glass and glass-ceramics show excellent osteoconductive and osteoinductive properties with a high degradation rate. The reason for this is related to the rate of active carbonated hydroxyapatite layer formed on their sur- 
face when in physiological or body fluids. The chemical composition of a bioactive glass determines its interaction with surrounding tissue. When glass is exposed to the body fluids, it initially releases alkali ions causing a local $\mathrm{pH}$ increase. Glass-ceramics are materials produced by controlled crystallization of certain glasses. In general, glass-ceramics show enhanced mechanical properties when compared to "parent" glass [22].

5) The purified xenograft Orthoss is a natural nanocrystalline carbonated hydroxyapatite $\mathrm{Ca}_{10-\mathrm{x}}\left(\mathrm{PO}_{4}\right)_{6-\mathrm{x}}\left(\mathrm{HPO}_{4}^{2-} \text { or } \mathrm{CO}_{3}^{2-}\right)_{\mathrm{x}}(\mathrm{OH})_{2-\mathrm{x}}($ where $0 \leq \mathrm{x} \leq 2)$ with a high porosity and large specific surface area as shown on Figure 4 by comparison with other bone substitutes.

\subsubsection{Dissolution Mechanisms}

Dissolution process is linked to the characteristics of the ceramic itself such structural aspect (block granules or powder), the porosity, the chemical composition $(\mathrm{Ca} / \mathrm{P})$, crystal and types of the surface area [18] [19]. Surrounding factors including $\mathrm{pH}$ and type of the solution where the material is immersed could modify the solubility of the ceramic. The order of solubility of calcium phosphate materials is as follows:

$$
\mathrm{ACP} \gg \mathrm{DCP}>\mathrm{TTCP}>\alpha-\mathrm{TCP}>\beta \text {-TCP } \gg \mathrm{HA}
$$

where ACP: amorphous calcium phosphate, DCP: dicalcium phosphate anhydrous, TTCP: tetracalcium phosphate, $\alpha$-TCP: alpha tricalcium phosphate, $\beta$-TCP: beta tricalcium phosphate and HA is hydroxyapatite. This order may however be modified by ionic substitutions.

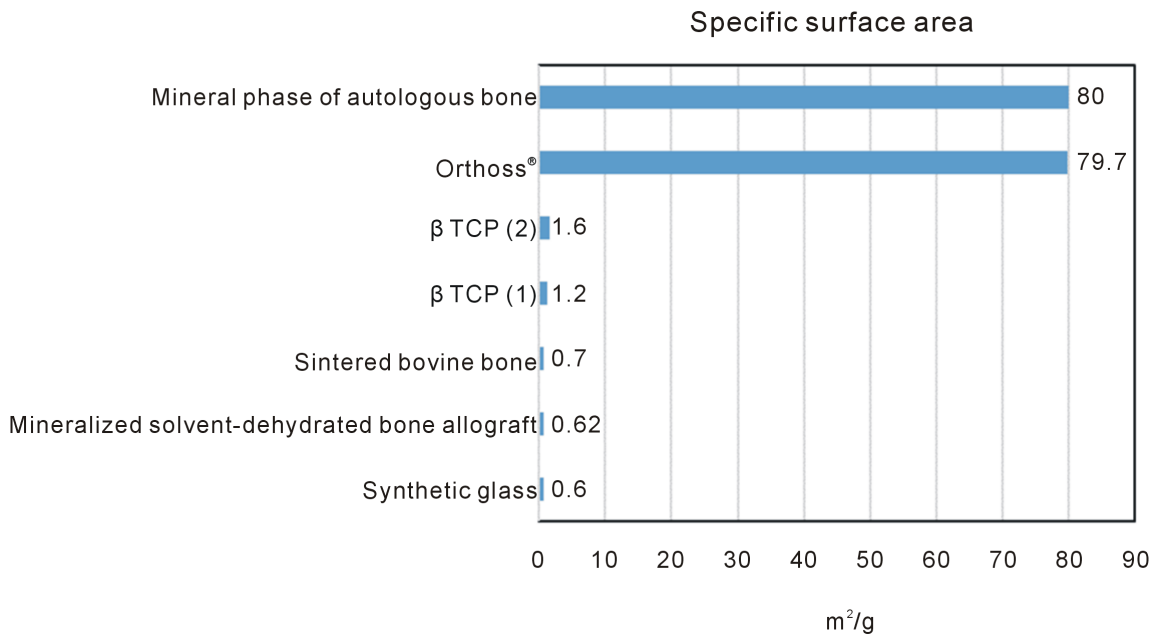

Figure 4. Specific surface area measured with gas absorption of commercial bone graft substitutes compared to Orthoss ${ }^{\circledR}$, mineral phase of autologous bone and others biomaterials. Samples were treated with vacuum at $100^{\circ} \mathrm{C}$ until no evolution of volatiles were observed. $\mathrm{N}_{2}$-adsorption isotherm was measured according to DIN-ISO 9277 at $77.4 \mathrm{~K}$ in a ASAP 2010 from Micromeritics. Applying the linearized BET-equation the measured values of adsorbed volume $(\mathrm{Va})$ vs. relative pressure $(\mathrm{p} / \mathrm{p} 0)$ were used to determine the amount of adsorbed molecules of a monolayer and hence the specific surface of the material, respectively. 


\subsubsection{Biological Properties}

Biological properties of bone substitutes must be provided by positive cellular responses and must avoid negative local or systemic effects. Many studies described the biocompatibility of calcium phosphates and purified xenografts without inflammatory or foreign body reactions. These substitutes have the capacity to establish a direct bond with the local bone. This can be demonstrated by the mechanical properties of the interface between the substitute and local bone. All bioactive materials are able to provide this link (ceramic products, purified xenografts and bioglasses).

In contact with biological fluids, all calcium phosphates undergo biodegradation, and bioresorption resulting in changes of the physicochemical properties of the material as disintegration, changes in porosity, dissolution of $\mathrm{Ca}$ and $\mathrm{P}$ and phase modifications. The physicochemical characteristics of the material (composition, microporosity and mode of fabrication) as well as the biological environment (degree of bony contact, type of bone, animal species, age and sex) are factors influencing the bioresorption.

Three mechanisms are leading to biodegradation/bioresorption: a physical abrasion or disintegration, a chemical dissolution inducing a local increase in calcium and phosphates ions, with formation of new phases, and a biological phase resulting from the activation of osteoclasts by ions, which will further contribute to the $\mathrm{pH}$ decrease due to the cellular activity and as a result to the biodegradation of the bone substitute.

There are two types of biologically-driven degradation: one is intracellular secondary to phagocytosis of small particles and one is extracellular by in situ dissolution.

In contact with bone substuitutes, we observed multinucleated giant cells resistant to tartaric acid phosphatase coming from macrophage cells. Many authors called them osteoclast-like cells [23]. We confirm now that these cells could be named true osteoclasts. The degradation provides crystals and particles incorporated inside the cytoplasm of the cells.

These mechanisms increase the concentration of calcium and phosphate ions and precipitation of new apatite crystals. This is followed by formation of needle-shaped biological crystals similar to the bone apatite.

After degradation and resorption true osteogenesis occurs inside the pores of the substitute and bone with osteoblasts and mineralized matrix appear around and within the macropores of the biomaterial.

Normal bone remodeling will take place with resorption/apposition [24] [25].

\subsubsection{Cellular Events}

Implantations of porous cylinders into cancellous bone in rabbit models showed a rapid interaction with local bone and invasion of the intratrabecular spaces of the bone substitute by connective tissue without sign of inflammation. Osteoblastic activity is due to the presence of absorbed proteins on the material.

The implanted calcium phosphate ceramic or purified xenograft is acting as a 
matrix and serves for differentiation of osteoblasts coming from bone marrow and precursor cells.

Osteoinduction has been observed after subcutaneous implantation of calcium phosphate ceramics in some experimental models, when mixed with bone marrow cells leading even to differentiation into mature bone. The bone substitute acts as a support for deposition of newly formed bone. These processes are similar to the early stages of embryonic bone development or fracture healing.

During differentiation the mesenchymal stem cells will acquire the specialized features of osteoblast to provide new bone (osteoconduction).

During these steps of bone differentiation there are two mechanisms:

1) Inside micropores (less than 10 microns) release of calcium, phosphate and carbonate ions due to local dissolution with neoformation of apatite crystals similar to host bone is an early calcification with crystals.

2) Inside macropores (more than 100 microns) the osteoconduction properties provides bone differentiation with differentiated cells (osteoblasts and osteoclasts and micro-vascularization). After 8 weeks haversian bone remodeling occurs and for this phase the macroposity and the interconnection between pores are important parameters.

But into non osseous sites the promotion of new bone takes place under influence of induction factors specific to the bone tissue [26] [27].

One important point is to provide an early intimate contact between the substitute and local bone to prevent micromovements of the interface which could lead to fibrous encapsulation.

The kinetic of the process of degradation/resorption/intracellular dissolution and cellular differentiation depends on chemical structure (HA, $\alpha$-TCP or $\beta$-TCP) the physical aspects (microporosity and macroporosity) and the implantation site.

Depending on the graft substitute origin and manufacturing process graft materials having the same chemical composition can differ dramatically in microporous structure and surface topography, and in consequence interaction with host tissue/cells (bioactivity)

An efficient bioactive material requires also high inner surface (specific surface area), an excellent hydrophilicity and capillary for a short term biologic fluids penetration and osseointegration.

Figure 5 shows an example of 6 weeks' implantation in rabbit femoral condyle defect of a xenogenic bone substitute (Orthoss ${ }^{\circledR}$ ) that early bone formation occurred around granules of porous, deproteinized xenogenic granules. A high level of osseointegration between xenograft granules and new bone can be observed on decalcified embedded in resin histological section (Paragon staining).

The impact of bone graft microstructure and surface microtopography on bone regeneration has been show in the rabbit sinus lift model [28]. In this study three hydroxyapatite based grafts of different origin (bovine or synthetic) or manufacturing process were compared regarding their performance and physical properties. The two bovine grafts displayed significantly higher bone quantities at 


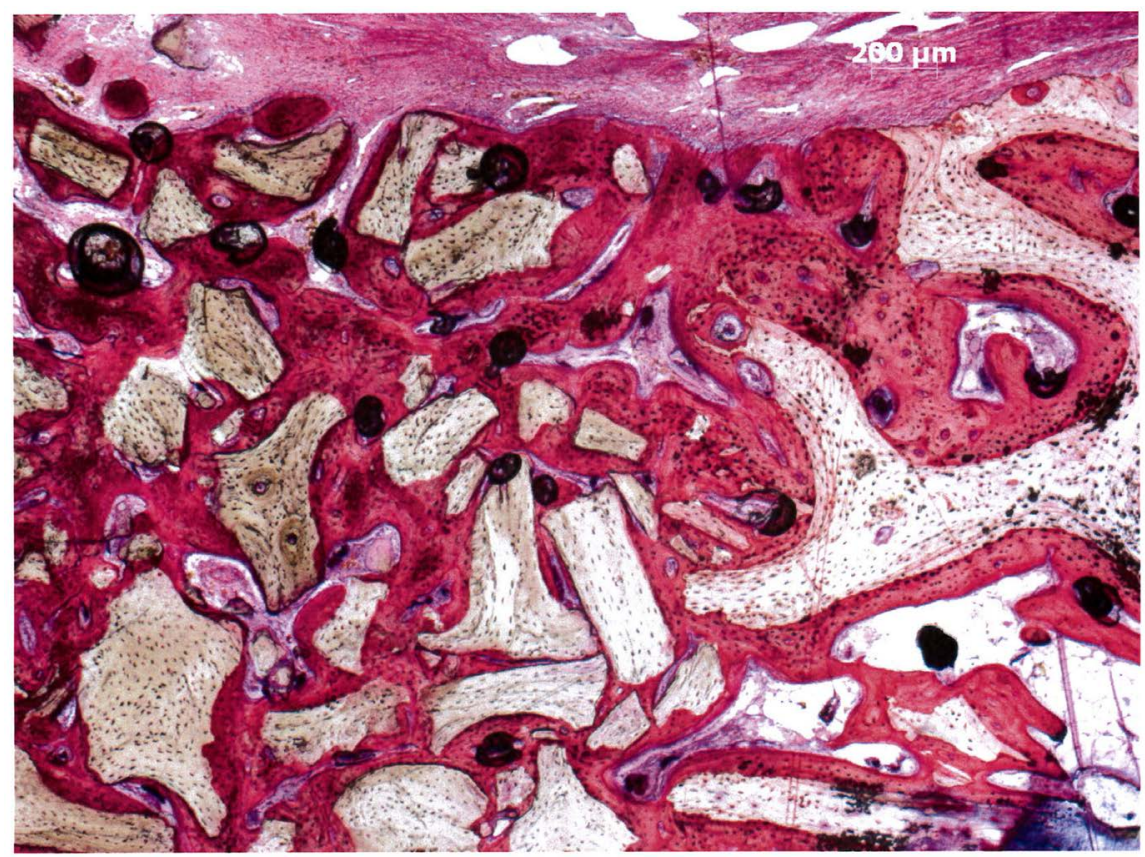

Figure 5. Histological section showing bone repair after 6 weeks' implantation with deproteinized, porous xenograft granules $\left(\mathrm{Orthoss}^{\mathbb{B}}\right.$ ) in rabbit femoral condyle model. Presented with permission of Prof. Gordon Blunn, Institute of Orthopedics and Musculoskeletal-Science, University College London.

12 weeks after implantation compared to the high-temperature sintered synthetic graft with absence of microporosity. Moreover, bone-to-graft contact (indicating osteoinductivity) was significantly higher for deproteinized, porous xenograft having the largest specific surface area combined with the presence of interconnected macropores and micropores (Figure 4). It seems that macroporosity and microporosity play important role in supporting new bone formation and osteoconductive properties manifested by higher bone-to-graft contact, and this graft characteristic is strongly affected by manufacturing processes. Table 1 summarizes the key properties of various bone grafts.

\subsubsection{Mechanical Properties of Biphasic Macroporous Ceramics and Xenografts}

The macroporous biphasic composites and purified xenograft allow centripetal bony ingrowth by differentiated cells which secure the resorption/ingrowth processes. Favorable pore size for bone formation is greater than 100 microns, but the resulting mechanical properties are insufficient. In fact, the resistance to axial compression gives a value in the region of 2.5 to $3 \mathrm{MPa}$, the material being very brittle and can be crushed between fingers. An animal model has allowed definition of the improvement in the mechanical properties associated with ingrowth by differentiated bone (collagen, carbonate ions and water) [29].

After implantation of cylinders of biphasic macroporous ceramic into distal femur of rabbit (cylinders of $6 \times 6 \mathrm{~mm}$ ) we compared mechanical properties and bone differentiation inside pores after 6 weeks. The mechanical properties of the 
Table 1. Summary of bone graft properties (-: none, +: low property, ++: high property).

\begin{tabular}{|c|c|c|c|c|c|c|}
\hline Graft type & $\begin{array}{l}\text { Autologous } \\
\text { iliac crest }\end{array}$ & $\begin{array}{l}\text { Decorticated } \\
\text { local bone }\end{array}$ & Allograft & DBM & $\begin{array}{c}\text { Synthetic } \\
\text { sintered } \\
\text { ceramics }\end{array}$ & $\begin{array}{c}\text { Deproteinized } \\
\text { porous } \\
\text { xenograft }\end{array}$ \\
\hline Osteoconductive & ++ & + & + & + & + & ++ \\
\hline Osteoinductive & + & + & $+/-^{*}$ & $+^{*}$ & - & - \\
\hline Resorption & + & + & - & + & + & + \\
\hline Biocompatibility & ++ & ++ & - & - & ++ & ++ \\
\hline Cost effective & + & + & - & + & - & - \\
\hline $\begin{array}{l}\text { Endogenous } \\
\text { growth factors }\end{array}$ & + & + & $+1-$ & + & - & - \\
\hline Macroporosity & ++ & + & + & - & + & ++ \\
\hline $\begin{array}{l}\text { Large volume } \\
\text { availability }\end{array}$ & - & - & + & + & + & ++ \\
\hline $\begin{array}{c}\text { Disease } \\
\text { transmission risk }\end{array}$ & - & - & + & + & - & - \\
\hline $\begin{array}{l}\text { Specific surface } \\
\text { area }\end{array}$ & + & + & - & - & - & ++ \\
\hline
\end{tabular}

${ }^{\star}$ Indicates variability resulting from the processing.

porous ceramic were improved by 2 to 2.5 with compression resistance increasing to $6.8 \mathrm{M}$ Pascal. This improvement of mechanical properties was associated properties was associated with bone differentiation inside the substitute (osteoclastic resorption, osteoblastic apposition).

These events are essential because they show the adaptation of the material to bone and this progressive bioactivity goes on a par with an increase in the mechanical qualities which with time approaches that of trabecular bone.

A main goal of a xenograft preparation is to obtain a bio-derived bone substitute made from highly purified bone mineral with similar micropores $(10-20$ microns) and macropores (100 - 300 microns) of natural cancellous bone. Compared to synthetic calcium phosphate porous ceramics the interconnectivity is higher and the mechanical properties before implantation are similar to synthetic bone substitutes (less than $5 \mathrm{MPa}$ ).

\subsubsection{Clinical Results}

1) Indications for metaphyseal defects as a result of fractures

Only 3 level II studies compared synthetic bone void filler with autograft and there was no statistically significant difference between synthetic bone substitutes and autografts [30] [31].

2) Bone grafts substitutes for opening-wedge osteotomies of the knee.

In an analysis of 1383 articles reduced to selection 56 articles after selection, Lask et al., [32] included 3.033 cases of osteotomy delayed union versus non-union rates were $3.6 \%$ for autograft and $4.6 \%$ for bone substitutes (no statistical significance) while the important parameter was the use or not of locking plates. 
3) Bone substitutes in spine surgery

The literature review of Medline identified over a total of 181 clinical studies, 40 studies on ceramics and xenografts and 39 studies on allografts [33]. For posterolateral fusion there is one level II study [34] and one level IV study [35]. These studies showed a statistically significant difference favoring synthetic or natural bone void fillers due to less VAS pain versus iliac crest bone graft.

In a monocentric retrospective study in France, Garin et al., [36] showed after a mean follow-up of 24 months that patients operated with Orthoss had spinal fusion according to radiographic analysis. For degenerative lumbar spine there were an average of 3 levels involved for fusion and 10 levels for correction of idiopathic scoliosis.

For postero-lateral fusion in lumbar degenerative spine and for deformities the use of xenograft and natural hydroxyapatite mixed with local bone decortication provides posterior fusion comparable to autologous bone.

4) Kubosch et al., [37] did an interesting retrospective study comparing allograft versus synthetic or highly-processed xenogeneic bone grafts. They identified 232 patients treated with various indications. Among this group there were 116 patients treated with a highly processed xenogeneic bone substitute (Orthoss $^{\circledR}$ from Geistlich Pharma AG, Wolhusen, Switzerland). Consolidation and fusion was obtained in 107 patients with only 2 failures and complications were correlated to clinical parameters as age, ASA risk classification BMI, smokers. In the group of allogeneic cancellous bone (ACB) there were 116 patients and $14.7 \%$ of complications occurred, so this publication confirms the indication of well characterized bone substitutes for bone defects, opening-wedge osteotomies in, spine surgery.

\subsection{Use of Bone Marrow Derived Stem Cells with Bone Substitutes}

Combination of bone substitutes, such as ceramics or xenograft, with bone marrow has shown significant osteogenic potential in vitro and in vivo [38], in a rabbit model of posterolateral fusion Delecrin et al., [39] found a significant increase in bone formation when bone marrow aspirate was added to ceramics, Curylo et al., [40] observed a 30\% greater increase in bone volume when bone marrow aspirate was mixed to autologous iliac crest graft in a rabbit model of posterolateral fusion.

Osteoprogenitor cells are more abundant in the iliac crest than the vertebral body space as described by Muscher et al., [41]. For fusion the use of bone marrow concentrated (BMC) could be of great interest particularly for atrophic pseudarthrosis. Recent works suggested the application of BMC associated with DBM or xenograft provide satisfactory results [42]. The different indications of autologous bone marrow have been described by Marmotti et al., [43] where the interest to add autologous bone marrow to macroporous xenograft in order to induce short term bone conduction was described. Recently, Jonhson [44] performed a prospective randomized study to compare BMC mixed with porous 
allograft to iliac crest autograft in lumbar fusion (25 patients followed 1 year). This study showed no statistical difference in fusion scores between allograft and autograft in lateral gutters, interbody cages or facet joints. A positive trend between CD 34+ counts and fusion was observed.

\section{Conclusions}

The calcium phosphate ceramics and xenograft derived bone substitutes are bioactive products and the closest relatives to the mineral phases of calcified tissues.

Literature review shows that these substitutes provide comparative results to the use of bone autografts for filling bone defects, in traumatology (metaphyseal areas), in tibia osteotomies and fusion for spine surgery. For surgical application, it is necessary to assess all the factors which allow one to obtain the best osteointegration for the types of operation planned, including:

- Chemical composition and dissolution patterns (HA, TCP impurities, ionic substitutions)

- Micro and macroporosity, size of crystals, inner surface area, pore structure and interconnectivity)

- Implantation zone, neighbouring tissue, age of patient, metabolic and confounding factors influencing bone development

While processed xenograft may provide a natural nanocrystalline carbonated hydroxyapatite with a well oriented macroporosity similar to cancellous bone, its developed inner surface gives a significant hydrophilicity and improves cells differentiation inside pores. The addition of bone marrow stem cells in such an osteoconductive material is able to provide the biological composite of cells and growth factors which is essential for optimal bone healing [36] [45]. Clinical results obtained by using this therapeutic paradigm, support its use as an alternative to autograft procedures, by combining the structural porosity of bone and the biological precursors of bone formation.

\section{Conflicts of Interest}

The authors declare that one of the authors is a consultant for Geistlich Pharma AG, Wolhusen, Switzerland.

\section{References}

[1] Giannoudis, P.V., Dinopoulos, H. and Tsiridis, E. (2005) Bone Substitutes: An Update. Injury, 36, S20-S27.

[2] De Long, W.G., Einhorn, T.A., Koval, K., Mc Kee, M., Smith, W., Sanders, R., et al. (2007) Bone Graft and Bone Graft Substitutes in Orthopaedic Trauma Surgery. A Critical Analysis. The Journal of Bone and Joint Surgery, 89, 649-658. https://doi.org/10.2106/JBJS.F.00465

[3] Fischer, C.R., Cassily, R., Cantor, W., et al. (2013) A Systematic Review of Comparative Studies on Bone Graft Alternatives for Common Spine Fusion Procedures. European Spine Journal, 22, 1423-1435. https://doi.org/10.1007/s00586-013-2718-4 
[4] Hannink, G. and Arts, C. (2011) Bioresorbability, Porosity and Mechanichal Strength of Bone Substitutes: What Is the Optimal for Bone Regeneration? Injury, 42, 522-525.

[5] Blohhuis, T.J. and Chrisarts, J.J. (2011) Bioactive and Osteoinductive Bone Graft Substitutes: Definition, Facts and Myths. Injury, 42, 526-529.

[6] Habibavic, P. and De Groot, K. (2007) Osteoinductive Biomaterials-Properties and Relevance in Bone Repair. Journal of Tissue Engineering and Regenerative Medicine, 1, 25-32. https://doi.org/10.1002/term.5

[7] Farrington, M., Matthewsi, Foreman, J., et al. (1998) Microbiological Monitoring of Bone Grafts: 2 Years Experience at a Tissue Bank. Journal of Hospital Infection, 38, 261-271.

[8] Zimmermann, G. and Moghaddam, A. (2011) Allograft Bone Matrix versus Synthetic Bone Graft Substitutes. Injury, 42, S16-S21.

https://doi.org/10.1016/j.injury.2011.06.199

[9] Samartzis, D., Shen, F.H., Goldberf, E.J. and An, H.S. (2005) Is Autograft the Gold Standard in Achieving Radiographic Fusion in One-Level Anterior Cervical Discectomy and Fusion with Rigid Anterior Plate Fixation? Spine, 30, 1756-1761. https://doi.org/10.1097/01.brs.0000172148.86756.ce

[10] Bohatyrewicz, A., Bohatyrewicz, R., Klek, R., et al. (2006) Factors Determining the Contamination of Bone Tissue Procured from Cadaveric and Multiorgan Donors. Transplantation Proceedings, 38, 301-304. https://doi.org/10.1016/j.transproceed.2005.11.087

[11] Loursen, M., Christensen, F.B., Bunger, C. and Lind, M. (2003) Optimal Handling of Fresh Cancellous Bone Graft: Different Peroperative Storing Techniques Evaluated by Inèvitro Osteoblast-Like Cell Metabolism. Acta Orthopaedica Scandinavica, 74, 490-496. https://doi.org/10.1080/00016470310017848

[12] Burchardt, H., Jones, H., Glowczewkie, F., et al. (1978) Freeze-Dried Allogeneic Segmental Cortical-Bone Grafts in Dogs. The Journal of Bone and Joint Surgery. American Volume, 60, 1082-1090.

[13] Marx, R.E. and Wong, M.E. (1987) A Technique for the Compression and Carriage of Autogenous Bone during Bone Grafting Procedures. Journal of Oral and Maxillofacial Surgery, 45, 988-989.

[14] Gazdag, A.R., Lane, J.M., Glaser, D. and Forster, R.A. (1995) Alternatives to Autogenous Bone Graft: Efficacy and Indications. Journal of the American Academy of Orthopaedic Surgeons, 3, 1-8.

[15] Peterson, B., Wang, P.G., Iglesias, R., Wang, J.C. and Lieberman, J.R. (2004) Osteoinductivity of Commercially Available Domineralized Bone Matrix: Preparation in a Spine Fusion Model. The Journal of Bone and Joint Surgery. American Volume, 86, 2243-2250. https://doi.org/10.2106/00004623-200410000-00016

[16] Grabowski, G. and Cornett, C.A. (2013) Bone Graft and Bone Graft Substitutes in Spine Surgery: Current Concepts and Controversies. The Journal of the American Academy of Orthopaedic Surgeons, 21, 51-60. https://doi.org/10.5435/JAAOS-21-01-51

[17] Bae, H.W., Zhao, L., Kanim, L.E., Wong, P., Delamarter, R.B. and Dawson, E.G. (2006) Intervariability of Bone Morphogenetic Proteins in Commercially Available Demineralized Bone Matrix Products. Spine, 31, 1299-1306. https://doi.org/10.1097/01.brs.0000218581.92992.b7

[18] Dorozhkin, S.V. (2013) Calcium Orthophosphate-Based Bioceramics. Materials, 6, 
3840-3942. https://doi.org/10.3390/ma6093840

[19] Dorozhkin, S.V. (2016) Calcium Orthophosphate $\left(\mathrm{CaPO}_{4}\right)$ : Occurrence and Properties. Progress in Biomaterials, 5, 9-70. https://doi.org/10.1007/s40204-015-0045-Z

[20] Kacarevic, Z.P., Kavehei, F., Houshmand, A., Franke, J., Smeets, R., Rimashevskiy, D., Wenisch, S., Schnettler, R., Jung, O. and Barbeck, M. (2018) Purification Process of Xenogenic Bone Substitutes and Their Impact on Tissue Reactions and Regeneration. The International Journal of Artificial Organs. http://journals.sagepub.com/doi/10.1177/0391398818771530

[21] Miron, R.J., Zhang, Q., Sculean, A., Buser, D., Pippenger, B.E., et al. (2016) Osteoinductive Potential of 4 Commonly Employed Bone Grafts. Clinical Oral Investigations, 10, 1724-1734.

[22] Renno, A.C.M., Bossini, P.S., Crovace, M.C., Rodrigues, A.C.M., Zanotto, E.D. and Parizotto, N.A. (2013) Characterization and in Vivo Biological Performance of Biosilicate. BioMed Research International, 13, 1-7.

[23] Basle, M.F., Chappard, D., Grizon, F., et al. (1993) Osteoclastic Resorption of Ca-P Biomaterials Implanted in Rabbit Bone. Calcified Tissue International, 53, 348-356. https://doi.org/10.1007/BF01351842

[24] Tapety, F.I., Amizuka, N., Voshima, K., Nomura, S., et al. (2004) A Histological Evaluation of the Involvement of Bio-Oss in Osteoblastic Differentiation and Matrix Synthesis. Clinical Oral Implants Research, 15, 315-324.

[25] Busenlechner, D., Tangl, S., Hair, B., Fugger, G., et al. (2008) Simultaneous in Vivo Comparison of Bone Substitutes in a Guided Bone Regeneration Model. Biomaterials, 29, 3195-3200. https://doi.org/10.1016/j.biomaterials.2008.04.021

[26] Ohgushi, H., Goldberg, V.M. and Caplan, A.I. (1989) Heterotopic Osteogenesis in Porous Ceramics Induced by Marrow Cells. Journal of Orthopaedic Research, 7, 568-578. https://doi.org/10.1002/jor.1100070415

[27] Manfro, R., Fonseca, F.S., Bortoluzzi, M.C. and Sendyk, W.-R. (2014) Comparative, Histological and Histomorphometric Analysis of 3 Anorganic Bovine Ocenogeneous Bone Substitutes: Bio-Oss, Bone-Fill, Gene-Ox Anorganic. Journal of Maxillofacial and Oral Surgery, 13, 464-470. https://doi.org/10.1007/s12663-013-0554-Z

[28] Lambert, F., Bacevic, M., Layrolle, P. and Schüpback, P. (2017) Impact of Biomaterial Micropography on Bone Regeneration: Comparison of 3 Hydroxyapatites. Clinical Oral Implants Research, 10, 201-207.

[29] Trécant, M., Delécrin, J., Royer, J. and Daculsi, G. (1994) Mechanical Canges in Macroporous Calcium Phosphate Ceramics after Implantation in Bone. Clinical Materials, 15, 233-240. https://doi.org/10.1016/0267-6605(94)90051-5

[30] Dickson, K.F., Friedman, J., Buckholz, J.G. and Flandry, F.D. (2002) The Use of Bone Source Hydroxyapatite Cement for Traumatic Metaphyseal Bone Void Filling. The Journal of Trauma, 53, 1103-1108. https://doi.org/10.1097/00005373-200212000-00012

[31] Bucholz, R.W., Carlton, A. and Holmes, R. (1989) Interporous Hydroxyapatite as a Bone Graft Substitute in Tibial plAteau Fracture. Clinical Orthopaedics and Related Research, 240, 53-62.

[32] Lask, N.J., Feller, J.A., Batty, C.M., Wasiak, J., et al. (2015) Bone Grafts and Bone Subsitutes for Opening-Wedge Osteotomies of the Knee: A Systematic Review. Arthroscopy, 31, 720-730.

[33] Millehouse, K.A., Kepler, C.K., Radoliff, K.E., et al. (2016) Bone Substitutes and Expanders in Spine Surgery. A Review of Their Fusion Efficacy International. Journal of Spine Surgery, 10, 33-37. 
[34] Lerner, T., Bullmann, V., Schulte, T.L., Schneider, M. and Lilyenqvist, V. (2009) A Level 1 Pilot Study to Evaluate Ultraporous B-Tricalcium Phosphate as a Graft Extender in Posterior Correction of Adolescent Idiopathic Scoliosis. European Spine Journal, 18, 170-179. https://doi.org/10.1007/s00586-008-0844-1

[35] Fujibayashi, S., Shikata, J., Tanaka, C., Matsushito, M., et al. (2001) Lumbar Posterolateral Fusion with Biphasic Calcium Phosphate Ceramic. European Spine Journal, 14, 214-221. https://doi.org/10.1097/00002517-200106000-00005

[36] Garin, C. and Boutrand, S. (2016) Natural Hydroxyapatite as a Bone Graft Extender for Posterolateral Spine Arthrodesis. International Orthopaedics, 10, 3140-3144.

[37] Kubosch, E.J., Bernstein, A., Wolf, L., Fretwurst, T., Nelson, K. and Schmal, H. (2016) Clinical Trial and In-Vitro Study Comparing the Efficacy of Treating Bony Lesions with Allografts versus Synthetic or Highly-Processed Xenogeneic Bone Grafts. BMC Musculoskeletal Disorders, 17, 1-17.

[38] Toquet, L., Rohanizadeh, R., Guicheux, J., Passuti, N., et al. (1999) Osteogenic Potential in Vitro of Human Bone Marrow Cells Cultured on Macroporous Biphasic Calcium Phosphate Ceramic. Journal of Biomedical Materials Research, 44, 98-108. https://doi.org/10.1002/(SICI)1097-4636(199901)44:1<98::AID-JBM11>3.0.CO;2-P

[39] Delecrin, J., Deschamps, C., Romih, M., Passuti, N., et al. (2001) Influence of Bone Environment on Ceramic Osteointegration in Spinal Fusion. The Spine Journal, 10, S110-S113.

[40] Curylo, L.J., Johnstone, B. and Petersilag, C.A. (1999) Augmentation of Spinal Arthrodesis with Autologous Bone Marrow in a Rabbit: Posterolateral Spine Fusion Model. Spine, 24, 434-439. https://doi.org/10.1097/00007632-199903010-00004

[41] Muschler, G.F., Boehm, C. and Easley, K. (1997) Aspiration to Obtain Osteoblast Progenitor Cells from Human Bone Marrow: Influence of Aspiration Volume. The Journal of Bone and Joint Surgery. American Volume, 79, 1699-1709.

[42] Hatzokos, J., Stavrilis, S.I. and Iosifidou, E. (2011) Autologous Bone Marrow Grafting Combined with DBM Improves Consolidation of Docking Site after Distraction Osteogenesis. The Journal of Bone and Joint Surgery. American Volume, 93, 671-678. https://doi.org/10.2106/JBJS.J.00514

[43] Marmotti, A., De Girolamo, L., Bonasia, D.E., Bruzzone, M., et al. (2014) Bone Marrow Derived Stem Cells in Joint and Bone Diseases: A Consike Review. International Orthopaedics, 38, 1787-1801. https://doi.org/10.1007/s00264-014-2445-4

[44] Johnson, R.G. (2014) Bone Marrow Concentrate with Allograft Equivalent to Autograft in Lumbar Fusions. Spine, 19, 695-700. https://doi.org/10.1097/BRS.0000000000000254

[45] Parker, R.M. and Malham, G.M. (2017) Comparison of a Calcium Phosphate Bone Substitute with Recombinant Human Bone Morphogenetic Protein-2: A Prospective Study of Fusion Rates, Clinical Outcomes and Complications with 24-Month Follow-Up. European Spine Journal, 26, 754-763.

https://doi.org/10.1007/s00586-016-4927-0 